\title{
STRESS AND FATIGUE ANALYSIS OF LANDING GEAR AXLE OF A TRAINER AIRCRAFT
}

\author{
Nikhil H P P $^{1}$ S R Basavaraddi ${ }^{2}$, K Manonmani ${ }^{3}$, P Mohan Swami ${ }^{4}$ \\ ${ }^{1}$ M.Tech Student (Design Engineering), KLE Dr. M.S Sheshgiri College of Engg \& Tech, Belgaum, Karnataka, India \\ ${ }^{2}$ Associate Professor, Mechanical Engineering, KLE Dr. M.S Sheshgiri College of Engg \& Tech, Belgaum, Karnataka, \\ India \\ ${ }^{3}$ Senior Manager, Stress Group, ARDC, HAL, Bangalore, Karnataka, India \\ ${ }^{4}$ Deputy Manager, Fatigue Group, ARDC, HAL, Bangalore, Karnataka, India
}

\begin{abstract}
The undercarriage or landing gear of an aircraft is the structure that supports an aircraft on the ground and allows it to taxi, takeoff and land. Among the various parts of landing gear, axle is the most critical component where the loads (landing and ground loads) act on the axle first, then transferred to the structure. In this study stress and fatigue analysis of the axle is performed to meet the strength and life requirements. The modeling of the axle is done using UniGraphics $(U G)$ software. Stress analysis is carried out using MSC Patran (pre-processing and post-processing)/Nastran (solver) for different landing loads (spin up, spring back, maximum vertical and drift) and ground handling loads (braking, taxing and turning). Stress analysis was carried out by both classical and FEM approaches and by comparing the results it was obvious that they were in correlation with one another. Fatigue analysis was also carried out for the axle using landing spectrum and ground handling spectrum to estimate the fatigue life. By the iteration process, the requirement of 10000 landings was satisfied.
\end{abstract}

Keywords: Static, Fatigue, Axle, Fatigue life, UniGraphics, MSC Patran, MSC Nastran

$* * *$

\section{INTRODUCTION}

The landing gear is that portion of the aircraft that supports the weight of the aircraft while it is on the ground. The landing gear contains components that are necessary for taking off and landing the aircraft safely. Some of these components are landing gear struts that absorb landing and taxiing shocks; brakes that are used to stop and, in some cases, steer the aircraft; nose wheel steering for steering the aircraft; and in some cases, nose catapult components that provide the aircraft with carrier deck takeoff capabilities.

The landing gear of modern aircraft consists of Tires, Wheels, Brakes, Landing leg and associated retraction equipment which represents a substantial unit of the aircraft [1]. It accounts for some $3 \frac{1}{2}$ to 5 per cent of the gross aircraft weight or 15 to 20 per cent of the structure weight of the Aeroplane. The landing gear is the principle support of the airplane when parked, taxiing, taking off, or when landing.

In this paper, stress and fatigue analysis of the landing gear axle is carried out. The strength criteria and life estimation of the component is carried out.

\subsection{Axle}

The axle is a hallow shaft, as we know that a hallow shaft is a stiffer than a solid shaft in bending. An axle is a central shaft for a rotating wheel or gear. The wheels are mounted on the axle. Thus axle should be able to take up the load of the wheels while landing safely.

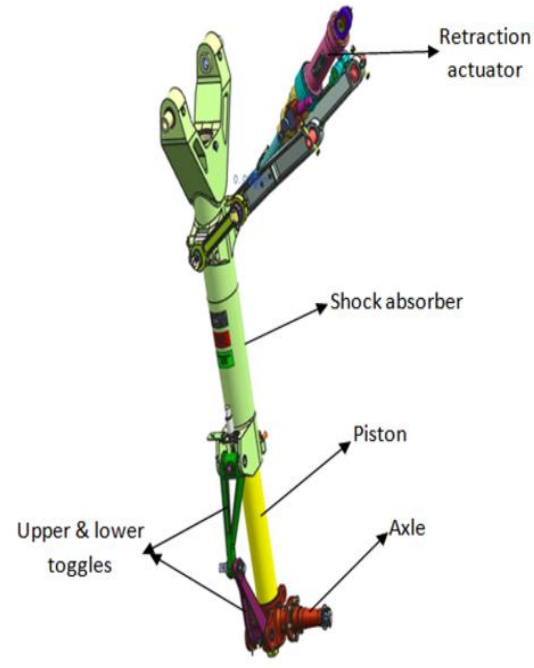

Fig -1: Landing Gear Arrangement

\section{STRESS ANALYSIS OF AXLE}

The axle is analyzed using linear static analysis. For the analysis MSC PATRAN is the pre-processor and postprocessor and MSC NASTRAN [4] is the solver.

The axle is made up of NCM Steel (Nickel, Chromium, Molybdenum Steel). NCM Steel is used in the aircraft industry due to the fact that it is having high strength to weight ratio. 


\subsection{Geometric Modeling}

The first step in the analysis of axle is geometry creation. The axle was imported from UNIGRAPHICS CAD tool by converting the file into parasolid model file. Fig-2 shows the geometry of the axle.

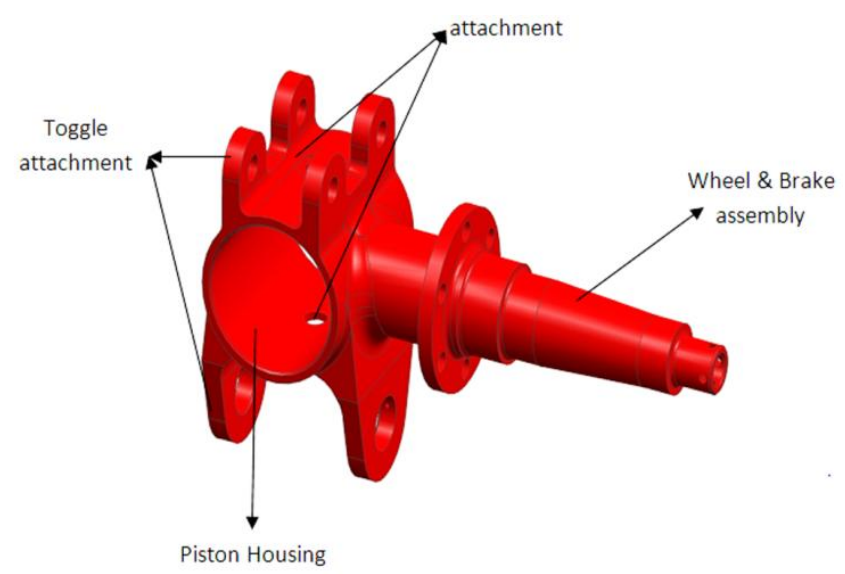

Fig -2: Geometry of Axle

\subsection{Meshing}

The second step in the analysis of axle is to create Finite Element (FE) model. Geometric model is meshed using 3-D tetrahedral elements. The rod elements are verified for their nodal connectivity with the tetrahedral elements in order to ensure that the load applied at the centroid of the brake and wheel assembly is properly transferred to the attachment structure.

The FE model of the axle is shown in Fig- 3.

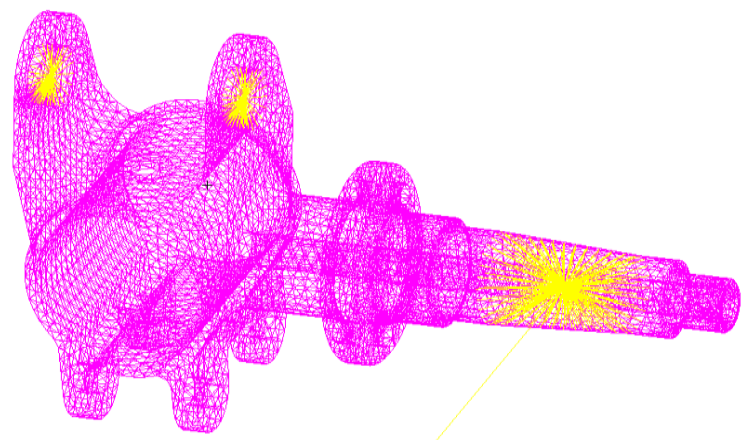

Fig -3: Geometrical Meshing of FE Model

\subsection{Assigning Material Properties}

The axle is made up of NCM Steel (Nickel, Chromium, Molybdenum Steel). NCM Steel is used in the aircraft industry due to the fact that it is having high strength to weight ratio.

Nickel - Chromium - Molybdenum - Steel (BS5S99D) / (AISI 4340)

- Chemical Composition:- C- 0.4, Si- 0.22, Mn- 0.55, Ni-

2.5, Cr- 0.65, Mo- 0.5, P- 0.025, S-0.015, Al-0.033

- Ultimate Tensile Strength:- 1230 - $1420 \mathrm{MPa}$
- Young's Modulus:- 210000MPa

- Poisson's Ratio:- 0.3

\subsection{Application of Loads and Boundary Conditions}

\section{Landing Cases}

$>\quad$ Two point level landing Spin-up

$>$ Two point level landing Spring-back

$>$ Two point level landing Max vertical

$>$ Drift landing Side Inboard

$>$ Drift landing Side outboard

\section{Ground Maneuvering Cases}

$>\quad$ Two pt braked roll (Hard braking)

$>\quad$ Two pt braked roll (Medium braking)

$>$ Turning outside- wheel

$>$ Turning inside-wheel

$>$ Pivoting

$>2 \mathrm{~g}$ taxiing

$>$ Static loads on the wheel

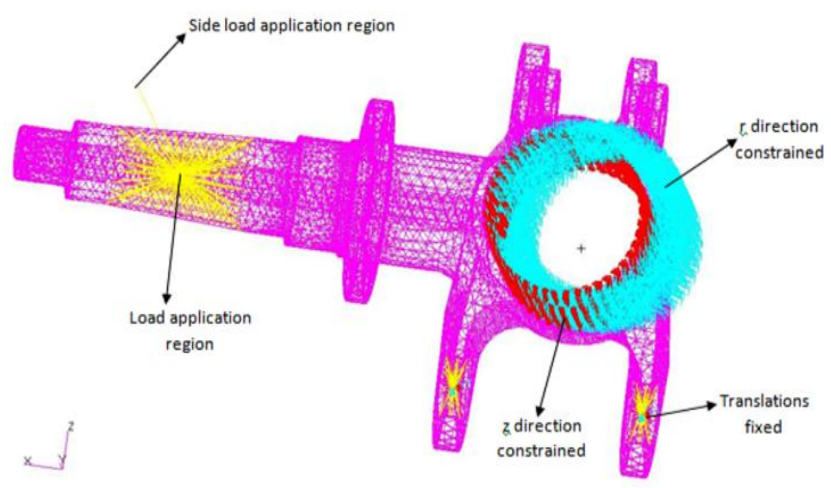

Fig -4: Boundary Conditions of Axle

\subsection{Stress Analysis Result Plots}

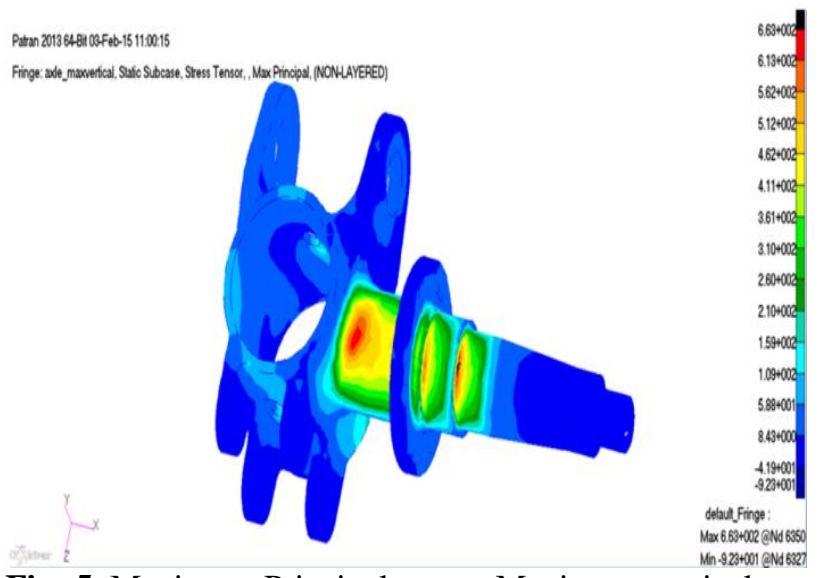

Fig -5: Maximum Principal stress- Maximum vertical case 


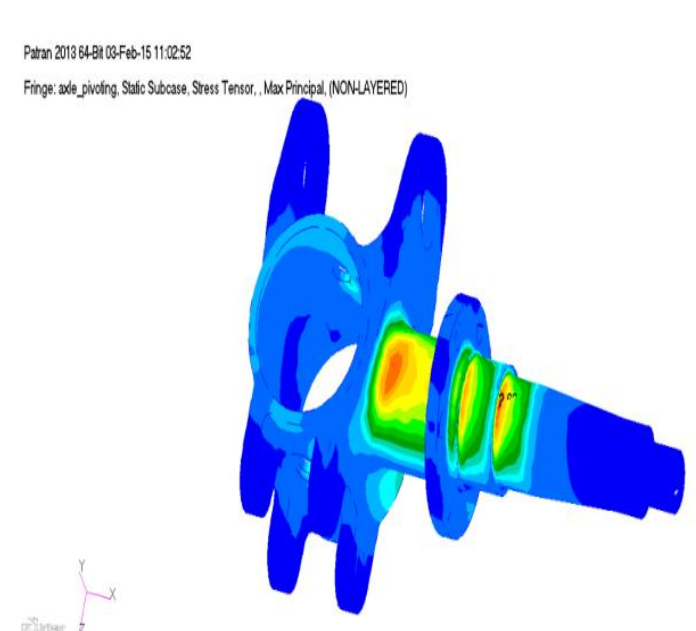

Fig -6: Maximum Principal stress- Pivoting case

\subsection{Stress Analysis by Classical Approach}

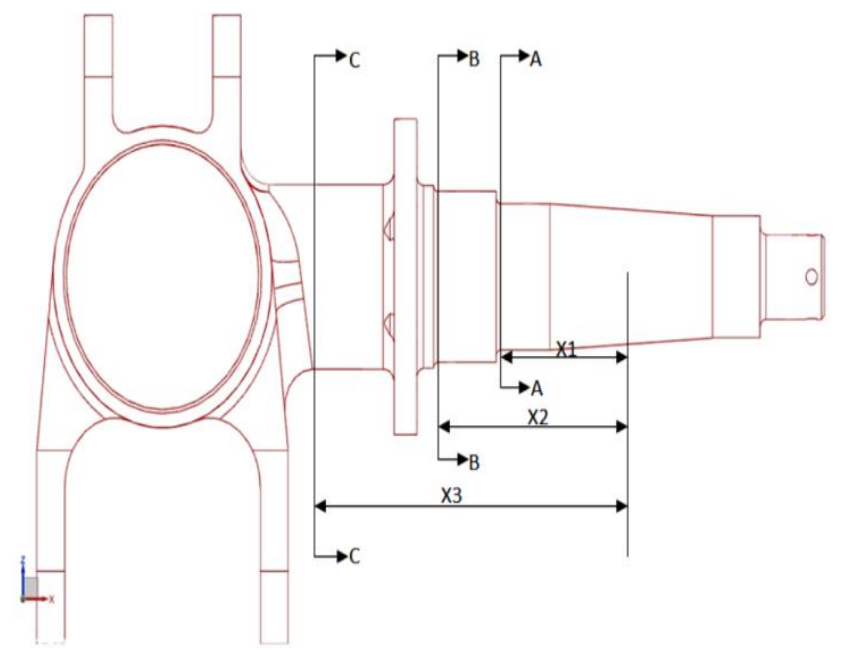

Fig -7: Critical sections of the axle

The classical approach results are compared with the FEA results at the critical sections shown in the Fig-7.

\subsection{Equations Used For Static Analysis}

Bending Moment $(\mathrm{M})=$ Arm length $* \sqrt{\mathrm{V}^{2}+\mathrm{D}^{2}}$

Bending Stress $(\sigma b)=\frac{\mathrm{M}^{*} \mathrm{y}}{\mathrm{I}}$

$=\frac{\mathrm{M} *\left(\frac{\mathrm{d} 0}{2}\right)}{\frac{\pi\left(\mathrm{d} 0^{4}-\mathrm{di}^{4}\right)}{64}}$

Shear Stress $(\tau)=\sqrt{\mathrm{V}^{2}+\mathrm{D}^{2}} /$ Area of C/s

Max Principal $=\frac{\sigma}{2}+\sqrt{\left(\frac{\sigma}{2}\right)^{2}+\tau^{2}}$

reserve factor
Table-1: At Section A-A

\begin{tabular}{|l|l|l|}
\hline Load Cases & $\begin{array}{l}\text { Classical } \\
\text { Approach } \\
\text { (Mpa) }\end{array}$ & $\begin{array}{l}\text { FEA } \\
\text { Approach } \\
\text { (Mpa) }\end{array}$ \\
\hline Spin-up & 576.791 & 597 \\
\hline Spring-back & 576.791 & 599 \\
\hline Maximum vertical & 474.276 & 512 \\
\hline Drift-Side inboard & 738.133 & 815 \\
\hline Drift-Side outboard & 16.740 & 23 \\
\hline Hard braking & 262.178 & 271 \\
\hline Medium braking & 220.497 & 238 \\
\hline Turning-outside wheel & 984.608 & 1090 \\
\hline Turning-inside wheel & 2.808 & 9.78 \\
\hline Pivoting & 183.858 & 203 \\
\hline 2g Taxiing & 367.715 & 405 \\
\hline Static loads on wheel & 183.858 & 203 \\
\hline
\end{tabular}

From Table-1, turning-outside wheel has maximum FEA value hence the reserve factor is 1.128

Table-2: At Section B-B

\begin{tabular}{|l|l|l|}
\hline Load Cases & $\begin{array}{l}\text { Classical } \\
\text { Approach } \\
\text { (Mpa) }\end{array}$ & $\begin{array}{l}\text { FEA } \\
\text { Approach } \\
\text { (Mpa) }\end{array}$ \\
\hline Spin-up & 525.65 & 538 \\
\hline Spring-back & 525.65 & 539 \\
\hline Maximum vertical & 432.22 & 462 \\
\hline Drift-Side inboard & 536.86 & 573 \\
\hline Drift-Side outboard & 62.47 & 81.6 \\
\hline Hard braking & 238.93 & 271 \\
\hline Medium braking & 200.95 & 238 \\
\hline Turning-outside wheel & 697.43 & 764 \\
\hline Turning-inside wheel & 8.4 & 9.78 \\
\hline Pivoting & 167.56 & 203 \\
\hline 2g Taxiing & 335.11 & 365 \\
\hline Static loads on wheel & 167.56 & 203 \\
\hline
\end{tabular}

From Table-2, turning-outside wheel has maximum FEA value hence the reserve factor is 1.6

Table-3: At Section C-C

\begin{tabular}{|l|l|l|}
\hline Load Cases & $\begin{array}{l}\text { Classical } \\
\text { Approach } \\
\text { (Mpa) }\end{array}$ & $\begin{array}{l}\text { FEA } \\
\text { Approach } \\
\text { (Mpa) }\end{array}$ \\
\hline Spin-up & 706.62 & 655 \\
\hline Spring-back & 706.62 & 658 \\
\hline Maximum vertical & 581.03 & 562 \\
\hline Drift-Side inboard & 562.84 & 573 \\
\hline Drift-Side outboard & 182.81 & 169 \\
\hline Hard braking & 321.19 & 325 \\
\hline Medium braking & 270.13 & 261 \\
\hline Turning-outside wheel & 704.26 & 657 \\
\hline Turning-inside wheel & 56.69 & 29.1 \\
\hline Pivoting & 225.24 & 223 \\
\hline 2g Taxiing & 450.48 & 405 \\
\hline Static loads on wheel & 225.24 & 203 \\
\hline
\end{tabular}

From Table-3, turning-outside wheel has maximum FEA value hence the reserve factor is 1.869 


\section{FATIGUE ANALYSIS OF AXLE}

The axle is required to have a safe life of 10000 landings as specified for the trainer aircraft. The reactions $(\mathrm{Kg})$ for different landing cases are calculated in accordance with the sinking speed.

\subsection{Life Estimation by Stress Life Method}

As the axle is used in the landing gear, the fatigue load spectrum will comprise landing loads and ground maneuvering loads. Load cycling spectra are derived for Main Landing Gear (MLG) fatigue cases with vertical and drag loads. A separate attachment is made at the center of the wheel and brake assembly where the tire is fitted for the action of side loads [2]. The MLG is designed for higher loads, hence the fatigue analysis in the present paper is carried out for the axle present in the MLG of trainer aircraft. The cycling load cases considered are: spin up to spring back, maximum vertical to zero load, drift landingside inboard to side outboard, braked roll cases- hard braking to static loads and medium braking to static loads, pivoting load to zero load, $2 \mathrm{~g}$ taxiing load, turning casesturning outside wheel to turning inside wheel.

The maximum and minimum stresses for each sinking speeds are taken proportional to the reactions developed at the wheel and the limit sinking speed stress. The occurrences (n) at different sinking speeds for all the fatigue cases are obtained from the military specifications for axle. The number of cycles to failure $(\mathrm{N})$ is calculated from the Constant life diagram for the material AISI 4340 , using the maximum and minimum stress values. The damage for all the levels in each case is found from the ratio of the occurrences per landing (n) to the number of cycles to failure $(\mathrm{N})$. These are summed for each case and the total damage/landing is calculated. According to Miner's theory, if this cumulative damage is equal to unity, then failure of plate takes place. The unfactored life of the plate is calculated by taking the reciprocal of the total damage/landing. The factored life is obtained by dividing the unfactored life by a scatter factor of 5 .

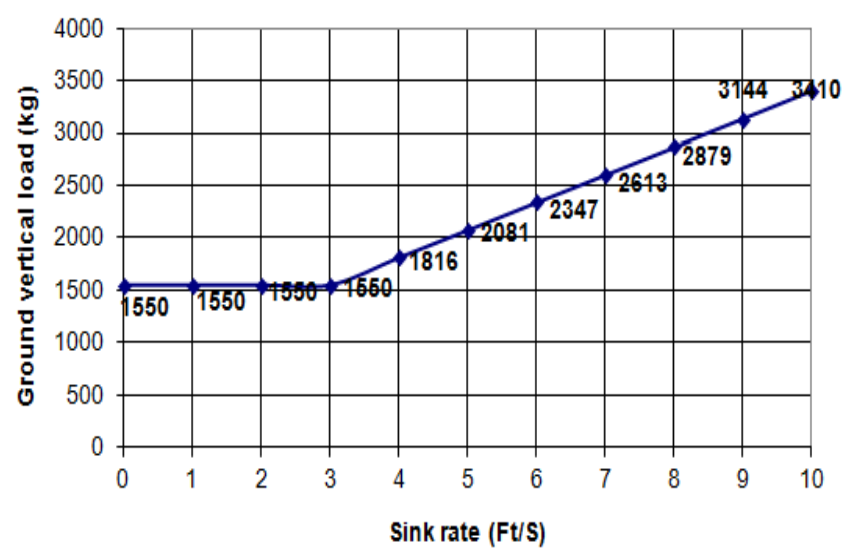

Fig -8: Main Landing gear vertical ground loads in Landing
Fig-8 shows the main landing gear vertical ground loads in landing, the graph is obtained with sink rate $(\mathrm{Ft} / \mathrm{S})$ along $\mathrm{X}$ axis v/s Ground vertical load $(\mathrm{Kg})$ along $\mathrm{Y}$ axis. These reactions for the respective sink rate are obtained by using Adams software.

\subsection{Equations used for Fatigue Analysis [3]}

$\begin{array}{ll}\text { Stress Ratio }(\mathrm{R}) & =\frac{\sigma \mathrm{min}}{\sigma \max } \\ \text { Stress Equivalent }\left(\mathrm{S}_{\mathrm{eq}}\right) & =\mathrm{S}_{\max }(1-\mathrm{R})^{0.65} \\ \log _{10} \mathrm{~N} & =7.52-1.96 \log _{10}\left(\mathrm{~S}_{\mathrm{eq}}-31.2\right) \\ \text { Damage } & =\frac{\text { No of Occurrence (n) }}{\text { No of Cycles }(\mathrm{N})} \\ \text { Life } & =\frac{1}{\text { Total Damage }} \\ \text { Safe Life } & =\frac{\text { Life }}{\text { Scatter Factor }}\end{array}$

Stresses are developed at three different locations, at these stressed locations safe life of the axle is found out for radius R1.5.

Table-4: Fatigue analysis results for fillet radius R1.5

\begin{tabular}{|l|l|l|l|}
\hline Locations & $\begin{array}{l}\text { Total } \\
\text { Damage/Landing }\end{array}$ & Life & $\begin{array}{l}\text { Safe } \\
\text { Life }\end{array}$ \\
\hline $\begin{array}{l}\text { Location } \\
1\end{array}$ & $7.81 \mathrm{E}-05$ & 12798 & 2559 \\
\hline $\begin{array}{l}\text { Location } \\
2\end{array}$ & $1.31 \mathrm{E}-05$ & 76193 & 15238 \\
\hline $\begin{array}{l}\text { Location } \\
3\end{array}$ & $7.31 \mathrm{E}-06$ & 136751 & 27350 \\
\hline
\end{tabular}

From the above Table- 4 it is clear that at location 2 and location 3, minimum requirement of 10000 landings for the trainer aircraft are satisfied. But at location 1 which has a safe life of 2559 landings doesn't satisfy the requirement of the trainer aircraft. Hence redesigning of the component is carried out.

Here in this case the fillet radius at location 1 is varied and safe life at location 1 is found out by iteration process shown below.

From Table-5 it is clear that at fillet radius R3 (max) the safe life of the component is 26529 landings, which has met the required criteria of 10000 landings. But redesigning the component for R3 ( $\max$ ) accounts for extra material and material cost. A small increase in weight of the axle accounts to a large impact on the aircraft. As a result of this, $\mathrm{R} 3$ which is the maximum value is discarded.

Now axle is redesigned with radius $\mathrm{R} 2.5$, the safe life of this is 10721 landings, this has met the required criteria of 10000 landings. 
Iteration process is also carried out with radius $\mathrm{R} 2$, the safe life obtained for this is 5562 landings, which is less than the required criteria of 10000 landings. For further development of the axle, radius R2.5 which has a safe life of 10721 landings is considered.

Table-5: Fatigue analysis results for varying fillet radius

\begin{tabular}{|l|l|l|l|l|}
\hline Iterations & $\begin{array}{l}\text { Fillet } \\
\text { Radius } \\
\mathrm{mm}\end{array}$ & $\begin{array}{l}\text { Total } \\
\text { Damage/Landing }\end{array}$ & Life & $\begin{array}{l}\text { Safe } \\
\text { Life }\end{array}$ \\
\hline 1 & $\begin{array}{l}\text { R3 } \\
(\mathrm{max})\end{array}$ & $7.54 \mathrm{E}-06$ & 132647 & 26529 \\
\hline 2 & R2.5 & $1.87 \mathrm{E}-05$ & 53608 & 10721 \\
\hline 3 & R2 & $3.60 \mathrm{E}-05$ & 27812 & 5562 \\
\hline
\end{tabular}

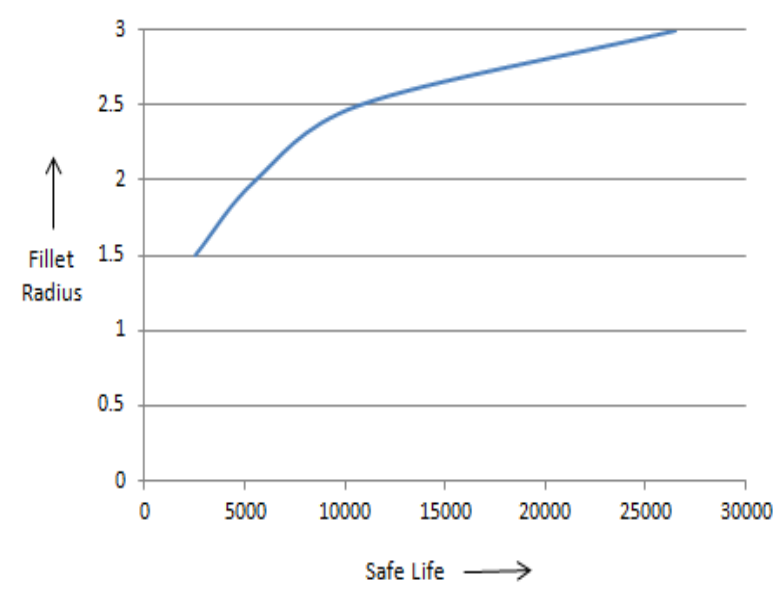

Fig -9: Safe Life variation with fillet radius

Fig-9 shows the variation of safe life with respect to varying fillet radius. It is evident from the results that safe life increases continuously with increase in fillet radius.

\section{CONCLUSION}

$>$ From the above results, It is observed that the maximum principal stress obtained for the axle is 1090 MPa for Turning outside wheel load case.

$>\quad$ The Reserve factor (RF) is 1.13

$>\quad$ The minimum RF value is greater than 1 , so the axle is safe from strength criteria.

$>$ Fatigue analysis is carried out to optimize the product and it is observed that for fillet radius R2.5 the design satisfies the requirement of 10000 landings.

\section{REFERENCES}

[1]. Conway H.G., Landing gear design, Chapman \& Hall Ltd, 1958

[2]. Bannantine J.A, Corner J.J., Handrock J.L., Fundamentals of metal fatigue analysis, Prentice Hall

[3]. Metallic materials properties development \& standardization (MMPDS), Jan-2003, U.S. Department of transportation, Federal Aviation Administration

[4]. "MSC/NASTRAN user's manual", user's guide. The MacNeal Schwendler Corporation, 1994 